\title{
A DIFFERENTIAL EQUATION FOR THE ENTROPY OF RURAL TOURISM IN THE CONTEXT OF COVID-19
}

\author{
BUCUR Amelia ${ }^{1}$ \\ ${ }^{1}$ Lucian Blaga University of Sibiu, amelia.bucur@ulbsibiu.ro
}

\begin{abstract}
The tourism industry was one of the world's greatest markets, until the world was affected by the COVID-19 pandemic. Now, tourism managers have to carefully assess the impact of epidemics on their businesses and develop new risk management methods to cope with the crisis. The current pandemic has created an opportunity for the development of rural tourism. This study aims to present a mathematical modeling of the entropy of rural tourism in the context of COVID-19 and a differential equation verified by this entropy. The model presented in this paper reflects the entropy of the preference for this type of tourism and a differential equation that models its variation. This paper aims to offer a tool to measure uncertainty regarding this topic. The model can be generalized and applied to any epidemic. The model could be used by specialists in quality management and mathematical modeling, managers of rural tourism organizations, local authorities, to estimate the entropy regarding how rural tourism has been and is still impacted by the COVID-19. The results obtained will help policy makers take necessary strategic and operational decisions, along with maximizing the profit of the rural tourism organization as well as the safety of the tourists.
\end{abstract}

KEY WORDS: the development of tools for measuring sustainable rural tourism; the impact of COVID-19 on rural tourism

\section{INTRODUCTION}

Rural tourism refers to a range of tourism activities that take place in the countryside, thus, this topic is of great interest to the contemporary world. In the past year, rural destinations have seen an increase in tourist activity, in contrast to urban destinations, as people have preferred to turn to safer or lowerrisk areas, with a low population number. This new orientation requires more investment in infrastructure, marketing, regional cooperation, and economic stimulus packages. [1-4]

Recently, many researchers have studied the impact of COVID-19 on the evolution of the financial market regarding tourism activity worldwide $[2,4]$ or in specific areas of the world [5-11], such as Malaysia, United Arab Emirates, Algeria, and others. The main methods used are mathematical statistics and mathematical models for stochastic processes.
The World Tourism Organization (UNWTO) offers data about the evolution of tourism across the globe. For example, figure 1 illustrates the changes in international tourist arrivals in Romania, comparing tourist activity from 2019 to the one from 2020.

The model presented in this paper reflects the entropy of rural tourism. This paper aims to offer a tool to measure uncertainty regarding this topic. The model could be used by specialists in quality management and mathematical modeling, managers of rural tourism organizations, local authorities, to estimate the entropy regarding how rural tourism has been and is still impacted by the COVID-19 pandemic.

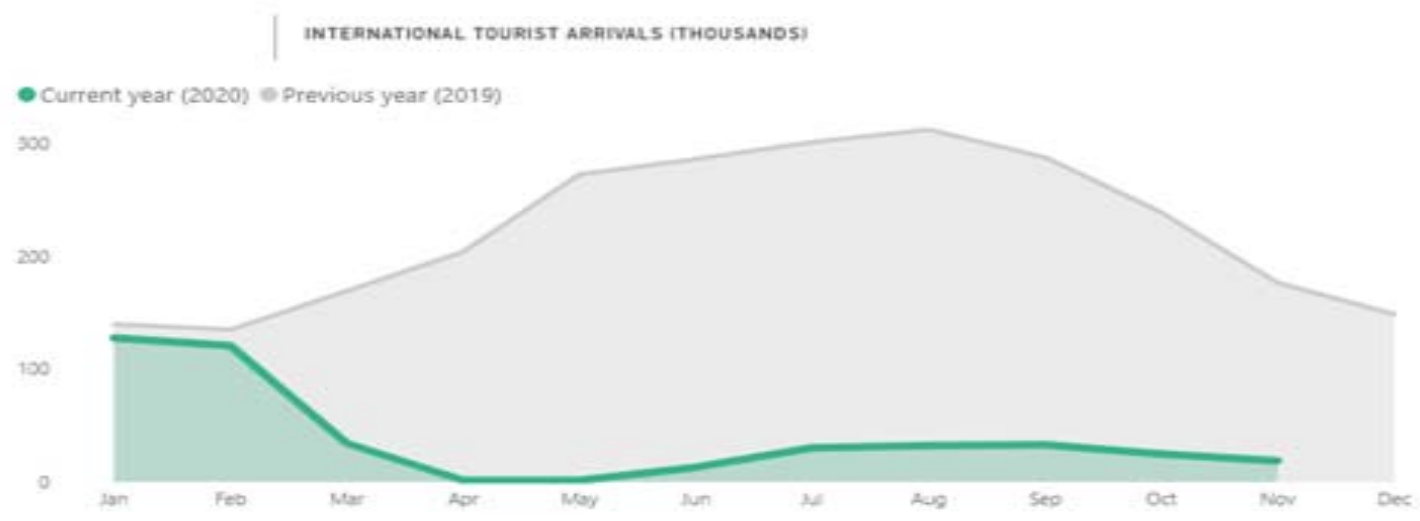

Figure 1. Changes in international tourist arrivals in Romania, due to COVID-19 [12]

\section{METHODS, RESULTS, DISCUSSION}

In this section is presented an entropic model, the mathematical model of the entropy of rural tourism in the context of COVID-19 and a differential equation verified by this entropy.
The aim of this model is to quantify the uncertainty regarding the impact of the COVID-19 pandemic on the preference for rural tourism.

The variables used for the mathematical model are numeric values associated to the following factors:

-economic factors at time $t: \boldsymbol{x}_{\mathbf{1}, \text { economic - number of }}^{t}$ tourists; $\boldsymbol{x}_{2, \text { economic }}^{t}$ - early departures; $\boldsymbol{x}_{3, \text { economic }}^{t}$ - three, four, 
and five-star hotels per capita; $\boldsymbol{x}_{\mathbf{4}, \text { economic }}^{\boldsymbol{t}}$ - restaurant per capita; $\boldsymbol{x}_{5, \boldsymbol{t}}^{\boldsymbol{t}}{ }_{\text {economic }}$ - regional tourism websites; $\boldsymbol{x}_{\mathbf{6}, \boldsymbol{e} \text { economic }}^{\boldsymbol{t}}$ - rail access has or doesn't have a rail link; $\boldsymbol{x}_{\mathbf{7}, \text { economic }}^{\boldsymbol{t}}$ gross domestic profit (GDP), where $\boldsymbol{x}_{\mathbf{1}, \text { economic }}^{t}, \ldots, \boldsymbol{x}_{\mathbf{7}, \text { economic }}^{t}$ are notations of the mean of the economic parameters of rural tourism organizations from a certain region or a certain state at time " $t$ ", parameters that we consider to be statistically independent.

-environmental factors at time $t: \boldsymbol{x}_{\mathbf{1}, \text { environmental - }}^{\boldsymbol{t}}$ percentage of local population that has access to clean and healthy water; $\boldsymbol{x}_{2, \text { environmental }}^{t}$ - tourist assessment of environmental health $(0-10) ; x_{3, \text { environmental - construction }}^{t}$ density per unit area; $\boldsymbol{x}_{\mathbf{4}, \text { environmental - number of natural }}^{\boldsymbol{t}}$ attractions and services in the region (such as swimming pools, horse-riding activities, food tasting events, skiing, etc.), where $\boldsymbol{x}_{1, \text { environmental }}^{\boldsymbol{t}}, \ldots, \boldsymbol{x}_{\mathbf{4}, \text { environmental }}^{\boldsymbol{t}}$ are notations of the mean of the environmental parameters of rural tourism organizations from a certain region or a certain state at time " $t$ ", parameters that we consider to be statistically independent.

-factors related to the safety of the tourists and of the region that the rural tourism organizations are part of at time $t$ : $\boldsymbol{x}_{1, \text { safety }}^{t}$ - tourist satisfaction regarding the safety of the region (people are wearing masks properly or not, proper social distancing etc.); $\boldsymbol{x}_{\mathbf{2}, \text { safety }}^{\boldsymbol{t}}$ - safety equipment from the region (masks, plastic screens, hand sanitizers, ambulances, hospitals, etc.); $\boldsymbol{x}_{\mathbf{3}, \text { safety }}^{\boldsymbol{t}}$ - assessment of whether local authorities apply laws that ensure the safety of the tourists $(0-10) ; \boldsymbol{x}_{4, \text { safety }}^{t}$ tourist satisfaction regarding the organization's safety measures against the spread of COVID-19 (testing employees regularly, checking temperatures of individuals, testing tourists before assigning them a room, asking for a negative test result from the last $48 \mathrm{~h}$, asking for a vaccination certificate, etc.); $\boldsymbol{x}_{\mathbf{5}, \text { safety }}^{\boldsymbol{t}}$ reproduction number, $r$, from the classic $S I R$ epidemic model [13], where $\boldsymbol{x}_{\mathbf{1}, \text { safety }}^{t}, \ldots, \boldsymbol{x}_{\mathbf{5}, \text { safety }}^{t}$ are notations of the mean of the safety parameters of rural tourism organizations from a certain region or a certain state at time " $t$ ", parameters that we consider to be statistically independent.

The means are calculated on a time interval of the form $\left[t_{0}, t^{l}\right]$, where $t_{0}, t^{l}$ is expressed in days.

The SIR model was developed by W.O. Kermack and A.G. McKendrick in the year 1927 and is known in the specialty literature as the classic epidemic model. They considered a dynamic model with three compartments, denoted by $S, I$, and $R$, in which the following transfers take place: from $S$ to $I$, and from $I$ to $R$.

In order to create the SIR model, the authors made the following suggestions:

- functions $S, I$, and $R$ are time functions $S=S(t), I=$ $I(t), R=R(t)$, differentiable on the interval $[0, \infty)$;

$-\beta$ rate of transmission, is the parameter that controls the transfer between $S$ and $I$. It represents the average number of contacts needed per time unit (per day) to infect a person;

$-\gamma / \mu$ is the transfer rate between $I$ and $R$, and it represents the recovery rate. The number $1 / \gamma$ shows the length of the time interval in which an individual becomes infected.

We choose the number of individuals, $N$, as an average value on the time interval $\left[t_{0}, t\right]$ for the population volume from the analyzed area, consisting of locals and tourists.
By assuming that $N$ is constant, we obtain that $S(t)+I(t)$ $+R(t)=N=$ the statistical population volume, at any time $t$. Based on these assumptions and the definitions of the parameters $\beta$ and $\gamma$, W.O. Kermack and A.G. McKendrick [13] obtained the following mathematical model, consisting of a nonlinear system of first order differential equations, the $S I R$ system:

$$
\left\{\begin{array}{c}
\frac{d S(t)}{d t}=-\beta S(t) \frac{I(t)}{N(t)} \\
\frac{d I(t)}{d t}=\beta S(t) \frac{I(t)}{N(t)}-\gamma I(t) . \\
\frac{d R(t)}{d t}=\gamma I(t)
\end{array}\right.
$$

The differential system $S I R$ always has initial conditions of the form $S(0)=S_{0}>0, I(0)=I_{0}>0, R(0)=R_{0}$, therefore solving it means solving a Cauchy problem. The initial conditions are the ones that describe the system at the initial time moment $t=0$.

The reproduction number shows how infectious the illness is - bifurcation parameter, is calculated with the formula: [14]

$$
r=\frac{\mathrm{S}_{0} \beta}{\mathrm{N} \gamma} .
$$

A small change in the reproduction number $r$, could lead to significant qualitative changes in the system, thus it is, in fact, a bifurcation parameter for the dynamic SIR system, the bifurcation taking place for $r$ close to value 1, therefore:

- if $r>1$, then function $I$, which represents the number of infectious individuals, has an increase up to its maximum value, after which its value decreases. In this case, the system forecasts an epidemic;

- if $r \leq 1$, then function $I$ is monotonically decreasing, from its initial value $I(0)$ to lower values. In this case, the SIR system shows that either there is no epidemic, or that the epidemic is going to end.

In order to develop the mathematical model of the entropy of rural tourism in the context of COVID-19, the author defined the entropy associated to this concept, based on the entropy formula established by Claude Shannon [15], which has been used for numerous generalizations and applications.

Let the following probabilities be $\boldsymbol{p}_{\boldsymbol{k} \text {,economic }}^{t}=$ $P\left(x_{k, \text { economic }}^{t}>a_{k}\right), \quad k=\overline{1,7} ; \quad p_{i, \text { environmental }}^{t}=$ $P\left(x_{i, \text { environmental }}^{t}>b_{i}\right), i=\overline{1,4} ; p_{j, \text { safety }}^{t}=P\left(x_{j, \text { safety }}^{t}>\right.$ $\left.\boldsymbol{c}_{\boldsymbol{j}}\right), \boldsymbol{j}=\overline{\mathbf{1 , 5}}$, with which are obtained the economic, environmental, and safety factors at time $t$ at higher levels than the real constants $\boldsymbol{a}_{\boldsymbol{k}}, \boldsymbol{b}_{\boldsymbol{i}}, \boldsymbol{c}_{\boldsymbol{j}}$.

Let the following be the probability field of the economic factors at time $t$ :

$$
\begin{gathered}
\text { Fecon }^{t}:\left(\begin{array}{cccc}
x_{1, \text { economic }}^{t} & x_{2, \text { economic }}^{t} & \ldots & x_{7, \text { economic }}^{t} \\
p_{1, \text { economic }}^{t} & p_{2, \text { economic }}^{t} & \ldots & p_{7, \text { economic }}^{t}
\end{array}\right) \\
p_{1, \text { economic }}^{t}+p_{2, \text { economic }}^{t}+\cdots+ \\
p_{7, \text { economic }}^{t}=1 .(3)
\end{gathered}
$$

Let the following be the probability field of the environmental factors at time $t$ :

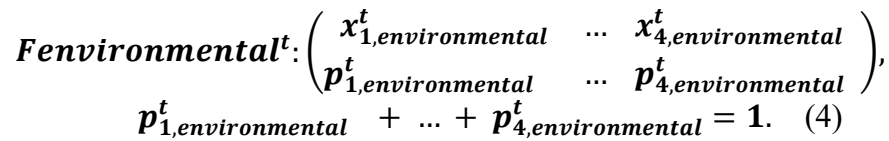


Let the following be the probability field of the safety factors at time $t$ :

$$
\begin{gathered}
\text { Fsafety }:\left(\begin{array}{cccc}
x_{1, \text { safety }}^{t} & x_{2, \text { safety }}^{t} & \cdots & x_{5, \text { safety }}^{t} \\
p_{1, \text { safety }}^{t} & p_{2, \text { safety }}^{t} & \ldots & p_{5, \text { safety }}^{t}
\end{array}\right), \\
p_{1, \text { safety }}^{t}+p_{2, \text { safety }}^{t}+\ldots+p_{5, \text { safety }}^{t}=1
\end{gathered}
$$

Definition 1. The author defines the mathematical model of the entropy of rural tourism in the context of COVID-19 at time $t$ as being an integral of the maximum entropy of the economic, environmental and safety factors multiplied by the function of stress caused by the COVID-19 pandemic at time $t$ $\left(\boldsymbol{S}:\left[\boldsymbol{t}_{\mathbf{0}}, \boldsymbol{t}^{\mathbf{1}}\right] \rightarrow[\mathbf{0}, \infty), \boldsymbol{S}=S(t)\right)$, with the formula:

$$
\begin{aligned}
& \int_{t_{0}}^{t^{1}} \max \left\{\begin{array}{c}
H\left(R T^{t}\right)= \\
-\sum_{k=1}^{7} p_{k, \text { economic }}^{t} \ln p_{k, \text { economic }}^{t} \\
-\sum_{i=1}^{4} \boldsymbol{p}_{i, \text { environmental }}^{t} \ln p_{i, \text { environmental }}^{t} \\
-\sum_{j=1}^{5} p_{j, \text { safety }}^{t} \ln p_{j, \text { safety }}^{t} \\
\times S(t) d t
\end{array}\right\} \times \\
& \times S(t) d t \text {. }
\end{aligned}
$$

In order to correctly define $H\left(\boldsymbol{R} \boldsymbol{T}^{\boldsymbol{t}}\right)$, we will agree that $\boldsymbol{p}_{\boldsymbol{k}, \text { economic }}^{\boldsymbol{t}} \boldsymbol{l n} \boldsymbol{p}_{\boldsymbol{k}, \text { economic }}^{\boldsymbol{t}}$ is equal to zero for $\boldsymbol{p}_{\boldsymbol{k}, \boldsymbol{e c c o n o m i c}}^{\boldsymbol{t}}=0$; $\boldsymbol{p}_{\boldsymbol{i} \text {,environmental }}^{\boldsymbol{t}} \ln \boldsymbol{p}_{\boldsymbol{i} \text {,environmental is equal to zero for }}^{\boldsymbol{t}}$ $\boldsymbol{p}_{i, e n v i r o n m e n t a l}^{t}=0 ;-\boldsymbol{p}_{j, \text { safety }}^{\boldsymbol{t}} \boldsymbol{l n} \boldsymbol{p}_{\boldsymbol{j}, \text { safety }}^{\boldsymbol{t}}$ is equal to zero for $\boldsymbol{p}_{j, \text { safet }}^{\boldsymbol{t}}=0$; which means that the function $-\boldsymbol{x} \ln \boldsymbol{x}$ is extended by continuity in $x=0$.

By defining the mathematical model of the entropy of rural tourism in the context of COVID-19 at time $t$, we can quantify the uncertainty regarding the preference for this type of tourism. If there is high uncertainty, the preference for rural tourism is low. Even more so, if uncertainty is heightened by a stress factor.

The author proposes the mathematical model of the entropy of rural tourism in the context of COVID-19 at time $t$ with the formula system (6) - (14) as being composed of the formula for the entropy of rural tourism in the context of COVID-19 at time $t$ from the interval $\left[t_{0}, t^{1}\right]$, multiplied by the function of stress caused by the COVID-19 pandemic at time $t$ [16] $\left(\boldsymbol{S}:\left[\boldsymbol{t}_{\mathbf{0}}, \boldsymbol{t}^{\mathbf{1}}\right] \rightarrow[\mathbf{0}, \infty)\right)$, to which the author added a restriction related to the Shannon entropy of the safety factors:

$$
\begin{gathered}
-\sum_{s=1}^{3} p_{s, \text { safety }}^{t} \ln p_{s, \text { safety }}^{t} \leq \alpha \\
p_{k, \text { economic }}^{t}= \\
P\left(x_{k, \text { economic }}^{t}>a_{k}\right), k=\overline{1,7}, \\
p_{i, \text { environmental }}^{t}= \\
P\left(x_{i, \text { environmental }}^{t}>b_{i}\right), i=\overline{1,4}, \\
p_{j, \text { safety }}^{t}=P\left(x_{j, \text { safety }}^{t}>c_{j}\right), \quad s=\overline{1,5}, \\
p_{1, \text { economic }}^{t}+p_{2, \text { economic }}^{t}+\cdots+\quad p_{7, \text { economic }}^{t}=1(11) \\
p_{1, \text { environmental }}^{t}+\ldots+p_{4, \text { environmental }}^{t}=1, \\
p_{1, \text { safety }}^{t}+p_{2, \text { safety }}^{t}+\cdots+p_{5, \text { safety }}^{t}=1, \\
a_{k}, b_{i}, c_{j} \alpha \geq 0 .
\end{gathered}
$$

The assessment of the model can be done by successively applying it at different times $t$. The model has the advantage that it can be easily understood and applied also by individuals who do not have a strong mathematical background. The constants from the proposed model can be chosen by the management of the organization according to their specifics and objectives and according to the professional experience of the manager.

Proposition 1. $H\left(\boldsymbol{R T}^{\boldsymbol{t}}\right) \geq \mathbf{0}$ for any probabilities $p_{k, e c o n o m i c}^{t}, k=\overline{1,7} ; \quad p_{i, e n v i r o n m e n t a l}^{t}, \quad i=\overline{1,4} ; p_{j, \text { safety, }}^{t}$ $\boldsymbol{i}=\overline{\mathbf{1 , 5}}, \quad$ with $\quad \boldsymbol{p}_{\mathbf{1}, \text { economic }}^{t}+\boldsymbol{p}_{\mathbf{2} \text {,economic }}^{t}+\cdots+$ $p_{7, \text { economic }}^{t}=1, p_{1, \text { environmental }}^{t}+p_{2, \text { environmental }}^{t}+\cdots+$ $p_{4, \text { environmental }}^{t}=1, \quad p_{1, \text { safety }}^{t}+p_{2, \text { safety }}^{t}+\cdots+$ $p_{5, \text { safety }}^{t}=1$.

Proof of Proposition 1. Based on the agreement that $\boldsymbol{p}_{\boldsymbol{k}, \boldsymbol{e} \text { conomic }}^{\boldsymbol{t}} \ln \boldsymbol{p}_{\boldsymbol{k}, \boldsymbol{e c c o n o m i c}}^{\boldsymbol{t}}$ is equal to zero for $\boldsymbol{p}_{\boldsymbol{k}, \boldsymbol{e c} \text { enomic }}^{\boldsymbol{t}}=0$; $-\boldsymbol{p}_{\boldsymbol{i}, \text { environmental }}^{\boldsymbol{t}} \boldsymbol{\operatorname { l n }} \boldsymbol{p}_{\boldsymbol{i}, \boldsymbol{t} \text { environmental }}^{\boldsymbol{t}}$ is equal to zero for $\boldsymbol{p}_{\boldsymbol{i}, \text { environmental }}^{\boldsymbol{t}}=0 ;-\boldsymbol{p}_{\boldsymbol{j}, \boldsymbol{s} \text { safety }} \boldsymbol{l n} \boldsymbol{p}_{\boldsymbol{j} \text {,safety }}^{\boldsymbol{t}}$ is equal to zero for $\boldsymbol{p}_{j, \text { safety }}^{\boldsymbol{t}}=0$, and the fact that the probabilities are quantities less than or equal to 1 , thus their natural logarithms are negative, the observation is correct.

Proposition 2. For any probabilities $\boldsymbol{p}_{\boldsymbol{k}, \text { economic, }}^{\boldsymbol{k}} \boldsymbol{k}=$ $\overline{\mathbf{1 , 7}} ; \quad p_{i, \text { environmental }}^{\boldsymbol{t}}, \boldsymbol{i}=\overline{\mathbf{1 , 4}}, \quad p_{j, \text { safety }}^{\boldsymbol{t}}, \boldsymbol{j}=\overline{\mathbf{1}, \mathbf{5}}, \quad$ with $p_{1, \text { economic }}^{t}+p_{2, \text { economic }}^{t}+\cdots+p_{7, \text { economic }}^{t}=$ $1, p_{1, \text { environmental }}^{t}+\ldots+p_{4, \text { environmental }}^{t}=$ $\mathbf{1 ,} \boldsymbol{p}_{1, \text { safety }}^{t}+\boldsymbol{p}_{2, \text { safety }}^{t}+\cdots+\boldsymbol{p}_{5, \text { safety }}^{t}=\mathbf{1}$, we have $H\left(R T^{t}\right) \leq \ln 7 \int_{t_{0}}^{t^{1}} S(t) d t$

Proof of Proposition 2. We use Jensen's inequality as inequality for real function, which is stated as follows:

Let $\boldsymbol{f}:[\boldsymbol{a}, \boldsymbol{b}] \rightarrow \boldsymbol{R}$ be a real function. This function is concave if, for any $\boldsymbol{x}_{1}, \boldsymbol{x}_{2} \epsilon[\boldsymbol{a}, \boldsymbol{b}]$ and any real constant $\lambda \epsilon[\mathbf{0}, \mathbf{1}]$, we have: $\boldsymbol{f}\left(\boldsymbol{\lambda} \gamma_{1}+(\boldsymbol{1}-\boldsymbol{\lambda}) \boldsymbol{\gamma}_{2}\right) \geq \boldsymbol{\lambda} \boldsymbol{f}\left(\boldsymbol{\gamma}_{1}\right)+(\boldsymbol{1}-\boldsymbol{\lambda}) \boldsymbol{f}\left(\boldsymbol{\gamma}_{2}\right)$.

We analyze the continuous and concave function $\boldsymbol{f}:[\boldsymbol{a}, \boldsymbol{b}] \rightarrow \boldsymbol{R}, \boldsymbol{\gamma}_{1}, \ldots, \gamma_{\boldsymbol{n}}$ from the range $[\boldsymbol{a}, \boldsymbol{b}]$ and the real numbers $\lambda_{1}, \ldots, \boldsymbol{\lambda}_{n} \geq \mathbf{0}$ with $\sum_{k=1}^{n} \boldsymbol{\lambda}_{k}=\mathbf{1}$. Jensen's inequality establishes the following relation:

$$
f\left(\sum_{k=1}^{n} \lambda_{k} \gamma_{k}\right) \geq \sum_{k=1}^{n} \lambda_{k} f\left(\gamma_{k}\right) .
$$

We will apply this inequality to:

- the concave and continuous function $f(\gamma)=-\boldsymbol{\gamma} \ln \gamma$,

- $[a, b]=[0,1]$,

- $n=7$,

- $\left(\gamma_{1}, \ldots, \gamma_{7}\right)=\left(p_{1, \text { economic }}^{t}\right.$,

,.., $\left.p_{7, \text { economic }}^{t}\right), p_{k, \text { economic }}^{t} \epsilon[0,1] k=1, \ldots, 7$,

- $\left(\lambda_{1}, \ldots, \lambda_{7}\right)=\left(\frac{1}{7}, \ldots, \frac{1}{7}\right), \sum_{k=1}^{7} \lambda_{k}=\sum_{k=1}^{7} \frac{1}{7}=1$.

We have

$$
\begin{aligned}
& -\left(\sum_{k=1}^{7} \frac{1}{7} p_{k, \text { economic }}^{t}\right) \ln \left(\sum_{k=1}^{7} \frac{1}{7} p_{k, \text { economic }}^{t}\right)- \\
& \sum_{k=1}^{7} \frac{1}{7} p_{k, \text { economic }}^{t} \ln p_{k, \text { economic }}^{t}
\end{aligned}
$$

This means that:

$$
\begin{aligned}
&-\frac{1}{7}\left(\sum_{k=1}^{7} p_{k, \text { economic }}^{t}\right)\left(\ln \frac{1}{7} \sum_{k=1}^{7} p_{k, \text { economic }}^{t}\right) \\
& \geq-\frac{1}{7} \sum_{k=1}^{7} p_{k, \text { economic }}^{t} \ln p_{k, \text { economic }}^{t}
\end{aligned}
$$

As $\sum_{\boldsymbol{k}=\mathbf{1}}^{\boldsymbol{7}} \boldsymbol{p}_{\boldsymbol{k}, \text { economic }}^{\boldsymbol{t}}=\mathbf{1}$, it implies that:

$-\sum_{k=1}^{7} p_{k, \text { economic }}^{t} \ln p_{k, \text { economic }}^{t} \leq-\ln \frac{1}{7}=\ln 7$. 
We apply inequality (15) to:

- the concave and continuous function $f(\gamma)=-\gamma \ln \gamma$,

- $[a, b]=[0,1]$

- $n=4$,

- $\left(\gamma_{1}, \ldots, \gamma_{4}\right)=\left(p_{1, e n v i r o n m e n t a l}^{t}\right.$,

,.., $\left.p_{4, \text { environmental }}^{t}\right), p_{i, \text { environmental }}^{t} \epsilon[0,1] i=1, \ldots, 4$,

- $\left(\lambda_{1}, \ldots, \lambda_{4}\right)=\left(\frac{1}{4}, \ldots, \frac{1}{4}\right), \quad \sum_{i=1}^{4} \lambda_{i}=\sum_{i=1}^{4} \frac{1}{4}=1$.

We have:

$$
\left.-\sum_{i=1}^{4} \frac{1}{4} p_{i, e n v i r o n m e n t a l}^{t}\right) \geq
$$

$-\sum_{i=1}^{4} \frac{1}{4} p_{i, \text { environmental }}^{t} \ln p_{i, \text { environmental }}^{t}$.

This means that:

$-\frac{1}{4}\left(\sum_{k=1}^{4} p_{k, \text { environmental }}^{t}\right)\left(\ln \frac{1}{4} \sum_{k=1}^{4} p_{k, \text { environmental }}^{t}\right)$

$\geq-\frac{1}{4} \sum_{k=1}^{4} p_{k, \text { environmental }}^{t} \ln p_{k, \text { environmental }}^{t}$

As $\sum_{\boldsymbol{k}=1}^{\mathbf{4}} \boldsymbol{p}_{\boldsymbol{k}, \text { environmental }}^{\boldsymbol{t}}=\mathbf{1}$, it implies that:

$-\sum_{k=1}^{4} p_{k, \text { environmental }}^{t} \ln \boldsymbol{p}_{k, \text { environmental }}^{t} \leq-\ln \frac{1}{4}=\ln 4$.

Then we apply Jensen's inequality to:

- the concave and continuous function $f(\gamma)=-\gamma \ln \gamma$,

- $[a, b]=[0,1]$,

- $n=5$,

- $\left(\gamma_{1}, \ldots, 5\right)=\left(p_{1, \text { safety }}^{t}\right.$,

,.., $\left.p_{5, \text { safety }}^{t}\right), p_{j, \text { safety }}^{t} \epsilon[0,1] j=1, \ldots, 5$,

- $\left(\lambda_{1}, \ldots, \lambda_{5}\right)=\left(\frac{1}{5}, \ldots, \frac{1}{5}\right), \sum_{j=1}^{5} \lambda_{j}=\sum_{j=1}^{5} \frac{1}{5}=1$

We have:

$-\left(\sum_{j=1}^{5} \frac{1}{5} p_{j, \text { safety }}^{t}\right) \ln \left(\sum_{j=1}^{5} \frac{1}{5} p_{j, \text { safety }}^{t}\right) \geq$ $\sum_{k=1}^{5} \frac{1}{5} p_{j, \text { safety }}^{t} \ln p_{j, \text { safety }}^{t}$.

This means that:

$$
\begin{aligned}
&-\frac{1}{5}\left(\sum_{j=1}^{5} p_{j, \text { safety }}^{t}\right)\left(\ln \frac{1}{5} \sum_{j=1}^{5} p_{j, \text { safety }}^{t}\right) \\
& \geq-\frac{1}{5} \sum_{j=1}^{5} p_{j, \text { safety }}^{t} \ln p_{j, \text { safety }}^{t}
\end{aligned}
$$

As $\sum_{j=1}^{\mathbf{5}} \boldsymbol{p}_{j, \text { esafety }}^{\boldsymbol{t}}=\mathbf{1}$, it implies that:

$-\sum_{j=1}^{5} \boldsymbol{p}_{j, \text { safety }}^{\boldsymbol{t}} \boldsymbol{l n} \boldsymbol{p}_{j, \text { safety }}^{\boldsymbol{t}} \leq-\ln \frac{\mathbf{1}}{\mathbf{5}}=\ln 5$.

Thus, we have $H\left(\boldsymbol{R} \boldsymbol{T}^{\boldsymbol{t}}\right) \leq$

$\max \{\ln 7, \ln 4, \ln 5\} \int_{t_{0}}^{t^{1}} S(t) d t=\ln 7 \int_{t_{0}}^{t^{1}} S(t) d t$

If we denote by $\boldsymbol{H}\left(\boldsymbol{R} \boldsymbol{T}^{\boldsymbol{z}}\right)$ the entropy of rural tourism on day $z$, with $z$ from the interval $\left[\boldsymbol{t}_{\mathbf{0}}, \boldsymbol{t}^{\mathbf{1}}\right]$, then the variation of the entropy from day $z$ to day $z+1$, meaning $\Delta \boldsymbol{H}\left(\boldsymbol{R} \boldsymbol{T}^{\boldsymbol{z}}\right)$, is proportional to the entropy from day $z$. Thus, it is equal to a proportionality factor $c$, multiplied by $\boldsymbol{H}\left(\boldsymbol{R} \boldsymbol{T}^{\mathbf{z}}\right)$ :

$$
\Delta \boldsymbol{H}\left(\boldsymbol{R} \boldsymbol{T}^{\mathbf{z}}\right)=\boldsymbol{c H}\left(\boldsymbol{R} \boldsymbol{T}^{\mathbf{z}}\right)
$$

which means that the difference between the entropy from day $z+1$ and day $z$ is

$$
\boldsymbol{H}\left(\boldsymbol{R} \boldsymbol{T}^{\mathbf{Z}+\mathbf{1}}\right)-\boldsymbol{H}\left(\boldsymbol{R} \boldsymbol{T}^{\mathbf{Z}}\right)=c \boldsymbol{H}\left(\boldsymbol{R} \boldsymbol{T}^{\mathbf{z}}\right),
$$

thus,

$$
\boldsymbol{H}\left(\boldsymbol{R} \boldsymbol{T}^{\boldsymbol{Z}+\mathbf{1}}\right)=(1+c) \boldsymbol{H}\left(\boldsymbol{R} \boldsymbol{T}^{\mathbf{z}}\right) .
$$

Writing this relation for $\boldsymbol{H}\left(\boldsymbol{R} \boldsymbol{T}^{\mathbf{z}}\right), \boldsymbol{H}\left(\boldsymbol{R} \boldsymbol{T}^{\mathbf{z}-\mathbf{1}}\right), \ldots, \boldsymbol{H}\left(\boldsymbol{R} \boldsymbol{T}^{\mathbf{1}}\right)$ we obtain the following equalities, which, after multiplying them and then dividing the left and right members of the obtained equality with the common term, will imply the fact that $\boldsymbol{H}\left(\boldsymbol{R} \boldsymbol{T}^{\mathbf{Z}}\right)$ is an exponential function:

$$
\begin{gathered}
\boldsymbol{H}\left(\boldsymbol{R} \boldsymbol{T}^{\mathbf{z}}\right)=(1+c) \boldsymbol{H}\left(\boldsymbol{R} \boldsymbol{T}^{\mathbf{z}-\mathbf{1}}\right) \\
\boldsymbol{H}\left(\boldsymbol{R} \boldsymbol{T}^{\mathbf{z}-\mathbf{1}}\right)=(1+c) \boldsymbol{H}\left(\boldsymbol{R} \boldsymbol{T}^{\mathbf{z}-\mathbf{2}}\right) \\
\boldsymbol{H}\left(\boldsymbol{R} \boldsymbol{T}^{\mathbf{1}}\right)=(1+c) \boldsymbol{H}\left(\boldsymbol{R} \boldsymbol{T}^{0}\right) \\
\boldsymbol{H}\left(\boldsymbol{R} \boldsymbol{T}^{\mathbf{z}}\right) \boldsymbol{H}\left(\boldsymbol{R} \boldsymbol{T}^{\mathbf{z}-\mathbf{1}}\right) \ldots \boldsymbol{H}\left(\boldsymbol{R} \boldsymbol{T}^{\mathbf{1}}\right)=(1+ \\
c)^{z+1} \boldsymbol{H}\left(\boldsymbol{R} \boldsymbol{T}^{\mathbf{z}-\mathbf{1}}\right) \boldsymbol{H}\left(\boldsymbol{R} \boldsymbol{T}^{\mathbf{z}-\mathbf{2}}\right) \ldots \boldsymbol{H}\left(\boldsymbol{R} \boldsymbol{T}^{\mathbf{0}}\right) \mid: \boldsymbol{H}\left(\boldsymbol{R} \boldsymbol{T}^{\mathbf{z}-\mathbf{1}}\right) \ldots \boldsymbol{H}\left(\boldsymbol{R} \boldsymbol{T}^{1}\right), \\
\boldsymbol{H}\left(\boldsymbol{R} \boldsymbol{T}^{\mathbf{z}}\right)=(1+c)^{z} \boldsymbol{H}\left(\boldsymbol{R} \boldsymbol{T}^{0}\right) .
\end{gathered}
$$

The exponential model (17) is a discrete model. However, even in continuous time, if we consider the variation of the entropy from one day to another proportional to the entropy from the previous day, with the proportionality factor $a$, we achieve yet again an exponential model. Thus, we obtain the differential equation verified by the entropy of rural tourism:

$$
\begin{aligned}
& \frac{\Delta \boldsymbol{H}\left(\boldsymbol{R} \boldsymbol{T}^{t}\right)}{\Delta t}=a \boldsymbol{H}\left(\boldsymbol{R} \boldsymbol{T}^{\boldsymbol{t}}\right), \\
& \frac{d \boldsymbol{H}\left(\boldsymbol{R} \boldsymbol{T}^{t}\right)}{d t}=a \boldsymbol{H}\left(\boldsymbol{R} \boldsymbol{T}^{\boldsymbol{t}}\right), \\
& \left.\boldsymbol{H}\left(\boldsymbol{R} \boldsymbol{T}^{\mathbf{0}}\right)=H_{0} \text { (a nonnegative real number }\right) \text {, } \\
& \frac{d \boldsymbol{H}\left(\boldsymbol{R} \boldsymbol{T}^{t}\right)}{\boldsymbol{H}\left(\boldsymbol{R} \boldsymbol{T}^{t}\right)}=a d t, \\
& \ln \left|\boldsymbol{H}\left(\boldsymbol{R} \boldsymbol{T}^{\boldsymbol{t}}\right)\right|=a t+\ln k=\ln e^{a t}+\ln k=\ln k e^{a t}, k>0, \\
& \boldsymbol{H}\left(\boldsymbol{R} \boldsymbol{T}^{\boldsymbol{t}}\right)=k e^{a t}, k \neq 0, \\
& \boldsymbol{H}\left(\boldsymbol{R} \boldsymbol{T}^{0}\right)=k e^{a \times 0}=k=H_{0},
\end{aligned}
$$

therefore

$$
\boldsymbol{H}\left(\boldsymbol{R} \boldsymbol{T}^{t}\right)=H_{0} e^{a t}
$$

\section{CONCLUSIONS}

The mathematical model of the entropy of rural tourism in the context of COVID-19 at time $t$ can highlight uncertainty related to the strong or weak points of rural tourism organizations, in order for them to cope with the crisis and to develop measures to increase the preference of tourists for their rural tourism, depending on different optimistic (more relaxed measures) or pessimistic (lockdown, strict measures against the spread of COVID-19, etc.) scenarios for the chosen region.

Rural tourism has created its own emerging market, characterized by factors with specific action and heterogeneous elements. The quality of touristic products and services is intended to become an element of competitive differentiation.

In order to continuously monitor and improve the quality of rural and touristic products, tourism organizations should take into consideration environmental, economic, and safety factors, as well as the tourist satisfaction, perception, and expectations.

The model presented in this paper reflects the entropy of this type of tourism and a differential equation verified by this entropy, and it can be generalized and applied to any epidemic. The model could be used by specialists in quality management and mathematical modeling, managers of rural tourism organizations, local authorities, to estimate the entropy regarding how rural tourism has been and is still impacted by the COVID-19 pandemic. The results obtained will help policy makers take necessary strategic and operational decisions, along with maximizing the profit of the rural tourism organization as well as the safety of the tourists. 


\section{REFERENCES}

1. Chang, C.-L.; McAleer, M.; Ramos, V. (2020) A Charter for Sustainable Tourism after COVID-19. Sustainability 12(9), 1-4 https://doi.org/10.3390/su12093671.

2. Aburumman, A.A. (2020) COVID-19 impact and survival strategy in business tourism market: the example of the UAE MICE industry. Humanit Soc Sci Commun, 7(171), 1$11 \mathrm{https} / / /$ doi.org/10.1057/s41599-020-00630-8.

3. Castanho, R.A.; Couto, G.; Pimentel, P.; Sousa, Á.; Carvalho, C.; Batista, M.d.G. (2020) The Impact of SARSCoV-2 Outbreak on the Accommodation Selection of Azorean Tourists. A Study Based on the Assessment of the Azores Population's Attitudes. Sustainability 12, 9990, 114, https://doi.org/10.3390/su12239990

4. Khalid, U.; Okafor, L.E.; Burzynska, K. (2021) Does the size of the tourism sector influence the economic policy response to the COVID-19 pandemic?. Current Issues in Tourism, 1-21 doi: 10.1080/13683500.2021.1874311.

5. Jaipuria, S.; Parida,R.; Ray,P. (2020) The impact of COVID-19 on tourism sector in India. Tourism Recreation Research, 1-17, doi: 10.1080/02508281.2020.1846971.

6. Nieto Masot, A.; Ríos Rodríguez, N. (2021) Rural Tourism as a Development Strategy in Low-Density Areas: Case Study in Northern Extremadura (Spain). Sustainability, 13, 239, 1-21 https://doi.org/10.3390/su13010239

7. Madani, A.; Boutebal, S.E.; Benhamida, H.; Bryant, C.R. (2020) The Impact of Covid-19 Outbreak on the Tourism Needs of the Algerian Population. Sustainability, 12(21), $8856,1-11$ https://doi.org/10.3390/su12218856.

8. Silva, L. (2021) The impact of the COVID-19 pandemic on rural tourism: a case study from Portugal, Anatolia. An
International Journal of Tourism and Hospitality Research, 1-4 doi: 10.1080/13032917.2021.1875015.

9. Polukhina, A.; Sheresheva, M.; Efremova, M.; Suranova, O.; Agalakova, O.; Antonov-Ovseenko, A. (2021) The Concept of Sustainable Rural Tourism Development in the Face of COVID-19 Crisis: Evidence from Russia. Journal of Risk and Financial Management, 14(1), 38, 1-19 https://doi.org/10.3390/jrfm14010038.

10. Rahmanov, F.; Aliyeva, R.; Rosokhata, A.; Letunovska, N. (2020) Tourism Management in Azerbaijan Under Sustainable Development: Impact of COVID-19. Marketing and Management of Innovations, 3, 195-207. http://doi.org/10.212272/mmi.2020.3-14.

11. Vaishar, A.; Št’astná, M. (2020) Impact of the COVID-19 pandemic on rural tourism in Czechia Preliminary considerations. Current Issues in Tourism 15 doi: 10.1080/13683500.2020.1839027.

12. https:/www.unwto.org/international-tourism-and-covid-19 (accessed on 20 March 2021).

13. Kermack, W.O.; McKendrick, A.G. (1927) Contributions to the mathematical theory of epidemics, Part 1, Proc. Roy. Soc. London Ser. A, 115, 700-721 https://doi.org/10.1098/rspa.1927.0118.

14. Simos, T.E.; Tsitouras, C.; Kovalnogov, V.N.; Fedorov, R.V.; Generalov, D.A. (2021) Real-Time Estimation of $R_{0}$ for COVID-19 Spread. Mathematics, 9(6), 664 https://doi.org/10.3390/math9060664.

15.Shannon, C.E. (1948) A mathematical theory of communication. Bell System Technical Journal, 27, 379423 and $623-656$. https://doi.org/10.1002/j.1538-7305.1948.tb01338.x.

16. Kang, S.-E.; Park, C.; Lee, C.-K.; Lee, S. (2021) The StressInduced Impact of COVID-19 on Tourism and Hospitality Workers. Sustainability, 1327 https://doi.org/10.3390/su13031327. 